\title{
VICTORIA CABRERA VALDÉS (1951-2004)
}

\author{
VICTORIA CABRERA VALDÉS (1951-2004)
}

\section{JOAQUÍN GONZÁLEZ ECHEGARAY (*)}

Hoy nuestra revista tiene que hacerse eco del gran pesar de la comunidad científica por la pérdida de una de las figuras más destacadas de la investigación prehistórica en el último cuarto del siglo XX: Victoria Cabrera Valdés (1951-2004) (Lám. I). En una vida relativamente breve, para lo que cabría esperar, consiguió ponerse en primera línea en el ranking internacional.

Vicky, nombre con el que la conocían todos sus colegas, era catedrática de Prehistoria en la Universidad Nacional a Distancia (UNED), y su presencia resultaba familiar en las más importantes reuniones profesionales de Europa y América, presentando siempre una aportación novedosa, bien fundada y a veces hasta un poco provocativa, lo que rompía la rutina y despertaba inquietud y controversia en los medios científicos. Solía hacerlo en colaboración con su marido, el Dr. Federico Bernaldo de Quirós, con quien trabajaba conjuntamente en el campo de la investigación, siguiendo la tradición de algunos matrimonios de científicos bien conocidos, como Pierre y Marie Curie en el campo de la Física, o François y Denise Bordes en el de la Prehistoria.

Su brillante labor como profesora universitaria puede calibrarse por la promoción de discípulos que, una vez presentadas sus tesis doctorales, han pasado ya a formar parte del mundo de la investigación prehistórica. Pero también por la iniciativa de promover coloquios científicos con proyección internacional, para estudiar en conjunto temas de especial relevancia. Es, por ejemplo, el caso del simposio de Madrid (1993) y el de Santoña (2003) o, a una escala nacional, los cursos de verano de la UNED en Ávila.

Victoria Cabrera era una prehistoriadora que no se conformaba con estudios y análisis especulati-

(*) Instituto para Investigaciones Prehistóricas. Avda. de Pontejos, 9. 39005 Santander.

Recibido: 30-VIII-05; aceptado: 23-IX-05.

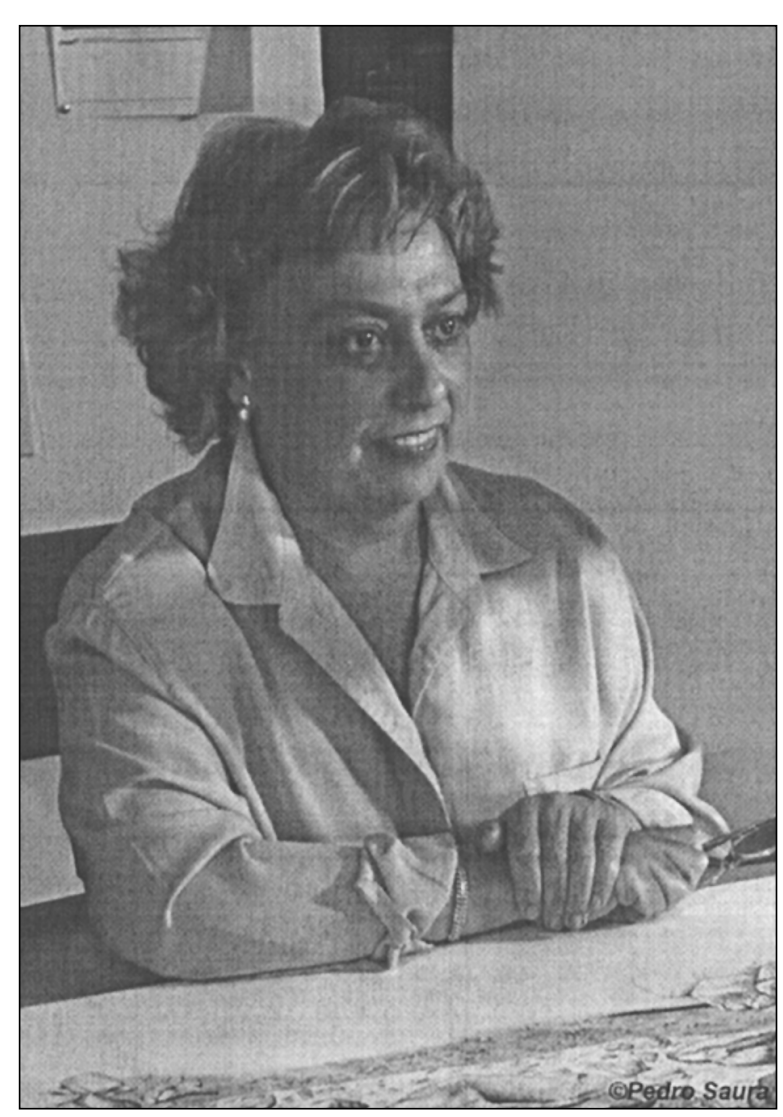

Lám. I. Victoria Cabrera Valdés. 2003.

vos, sino que estaba volcada en el trabajo de campo y la experiencia directa, de donde sacaba sus propias conclusiones y teorías. Ya desde muy joven tomó parte activa en excavaciones, como las cuevas de la Sarsa, Tito Bustillo y el abrigo de Tamajón. Después asumió responsabilidades de dirección en Hornos de la Peña y especialmente en Cueva Chufín. Pero el yacimiento que iba a quedar vinculado a su vida científica de forma definitiva era la famosa Cueva del Castillo (Puente Viesgo, Santander). 
Victoria Cabrera, que había sido discípula predilecta del Dr. Almagro Basch, defendió su tesis doctoral en la Complutense en 1978 sobre las antiguas excavaciones de Obermaier en la Cueva del Castillo, de las que tanto se ha hablado, pero que hasta entonces permanecían aún prácticamente inéditas. La tesis, que resultó un trabajo excelente y de interés extraordinario, sería publicada después en 1984 con el título El Yacimiento de la Cueva de «El Castillo» por el C.S.I.C. dentro de la colección Bibliotheca Praehistorica Hispana, tomo XXII. A partir de aquí y con su exhaustivo conocimiento del yacimiento y sus problemas, se decidió valientemente a continuar las antiguas excavaciones que habían sido interrumpidas el año 1914. En el ámbito de la Prehistoria, todo el mundo esperaba una reanudación de los trabajos en esta cueva, ahora ya con los métodos modernos. Sin embargo, nadie se había atrevido a llevarla a cabo, dada la inmensidad y complejidad de la obra, las dificultades técnicas y económicas, y la audacia que suponía hacerse cargo de un yacimiento que en su día fue la empresa científica más importante dentro del mundo de los estudios prehistóricos, y en la que habían tomado parte personalidades tan destacadas como H. Obermaier, H. Breuil, P. Wernert, P. Teilhard de Chardin y otros.

Desde 1980 hasta el año de su muerte, y más acá puesto que Federico Bernaldo de Quirós continúa con la obra, las campañas de excavaciones vienen sucediéndose ya cada año con el lento ritmo que hoy requieren estas investigaciones, pero con unos resultados espectaculares, que han suscitado el interés y a veces la discusión por parte de toda la comunidad científica. Por ejemplo, el hecho de que el famoso Auriñaciense antiguo del Castillo -nivel 18- haya podido ser datado por Cabrera con todas las garantías en una fecha tan temprana como el 38500 y el 40000 B.P. y de que en él aparecieran obras de arte, o que en el Musteriense -nivel 21- hayan podido registrarse ciertas técnicas en el trabajo del sílex, que hasta ahora se atribuían en exclusiva al Paleolítico Superior, han causado una verdadera explosión en los medios científicos y han contribuido a que el tema de la transición del Paleolítico Medio al Superior constituya uno de los asuntos clave en las publicaciones y simposios por parte de los prehistoriadores de todo el mundo.

Aunque las tesis de Cabrera hayan sido objeto de múltiples controversias, nadie ha puesto en duda la honestidad y competencia de Victoria Cabrera en sus trabajos, y hoy en día la mayor parte de los prehistoriadores da la razón a sus interpretaciones y reconoce que el yacimiento del Castillo constituye uno de los puntos clave en toda Europa para entender ciertos procesos fundamentales.

Se nos ha ido, pues, Victoria Cabrera quizá cuando más la necesitábamos. Pero ahí nos queda el testimonio de su valentía en defensa de la objetividad científica. A él permanecerá vinculado también el recuerdo de su gran personalidad, como una mujer sencilla, amable, preocupada por los demás y fiel a la amistad. Descanse en paz. 